\title{
Complex competence-oriented tasks for the training of specialized professionals
}

\author{
Victor Kalyuzhin ${ }^{1}$, Fedor Karavaytsyev ${ }^{1}$, Vera Shchukina, ${ }^{2, *}$ \\ ${ }^{1}$ Siberian State University of Geosystems and Technologies, 10, Plakhotnogo St., Novosibirsk, \\ 630108, Russia \\ ${ }^{2}$ Industrial University of Tyumen, 38, Volodarsky St., Tyumen, 625000, Russia
}

\begin{abstract}
The article discusses the experience of using competenceoriented tasks in the organization of the educational process in the discipline "Metrology, standardization and certification in geodesy and cadastre." The advantages and problems of the competence-based approach, the need to develop didactic and methodological support, and the importance of competence-oriented tasks in the formation of students' competencies are noted. From the position of a systematic approach, the activities of students in the framework of competence-oriented tasks are reviewed. As a result, it was revealed that the current level of competence formation depends on the correctness of the comparison of the basic elements (levels) of competencies with the substantive part of the discipline. To solve the problem of choosing competencies for the discipline, an approach has been proposed within which the concepts have been introduced: the indirect and direct influence of the discipline on the formation of competence and the proposed criteria values. Further research in this area may be related to the search for the optimal combination of types of tasks in a complex competence-oriented task.
\end{abstract}

\section{Introduction}

Metrology penetrates into all areas of human production, where it is necessary to make quantitative and qualitative assessments of measurement results. Measurements in land management and cadastre are the main source for determining the location and size of territories, for example, the boundaries of municipalities, territorial zones, land plots and real estate objects. Here, metrology is designed to ensure the required accuracy and quality of determining the geospatial data of cadastral objects in the Unified State Register of Real Estate [1,2].

In this context, the development of professional competencies for undergraduate enrolled in the direction of preparation "Land management and cadastre" (bachelor) in the field of metrology, including standardization and certification is an urgent task.

Now the educational process in universities is focused on the formation of the ability and readiness of graduates to effective and productive activities in various professional and socially significant situations, i.e. the formation of key competencies [3].

\footnotetext{
* Corresponding author: schukinavn@tyuiu.ru
} 
A number of publications are devoted to the issue of the implementation of a competence-based approach in a higher education institution: A.L. Andreev, V.I.Baydenko, E.V. Bondarevskaya, I.A. Zimney, and others [4], where various aspects of its implementation in the higher education system are considered. They distinguish both positive results and problem situations.

All researchers note that the main advantage of the competence-based approach (CBA) is the possibility of adapting the educational process and training a specialist to the demands of the labor market.

The main problem situation is the incompleteness of the CBA theory of higher education, which results in difficulties in the technological and organizational and regulatory aspects of its implementation in universities. Therefore, the didactic and methodological support of CBA is now in demand, determining the methods and practical steps of the organization of vocational education.

Among the ways to implement a CBA, researchers call gaming technology, professionally-oriented situations, problem-based learning, role-playing and business games, project organization, brainstorming, etc.

It is considered that competence-oriented tasks should be considered as the main means of forming competencies [20]. Since they form the willingness and ability of students to find the right solutions in a particular professional situation.

\section{Theoretical and methodical basis}

Competence-oriented tasks (COT) are an integrated didactic unit, which includes the content, technology of training, the activity of the teacher and students and the assessment of the quality of education [20].

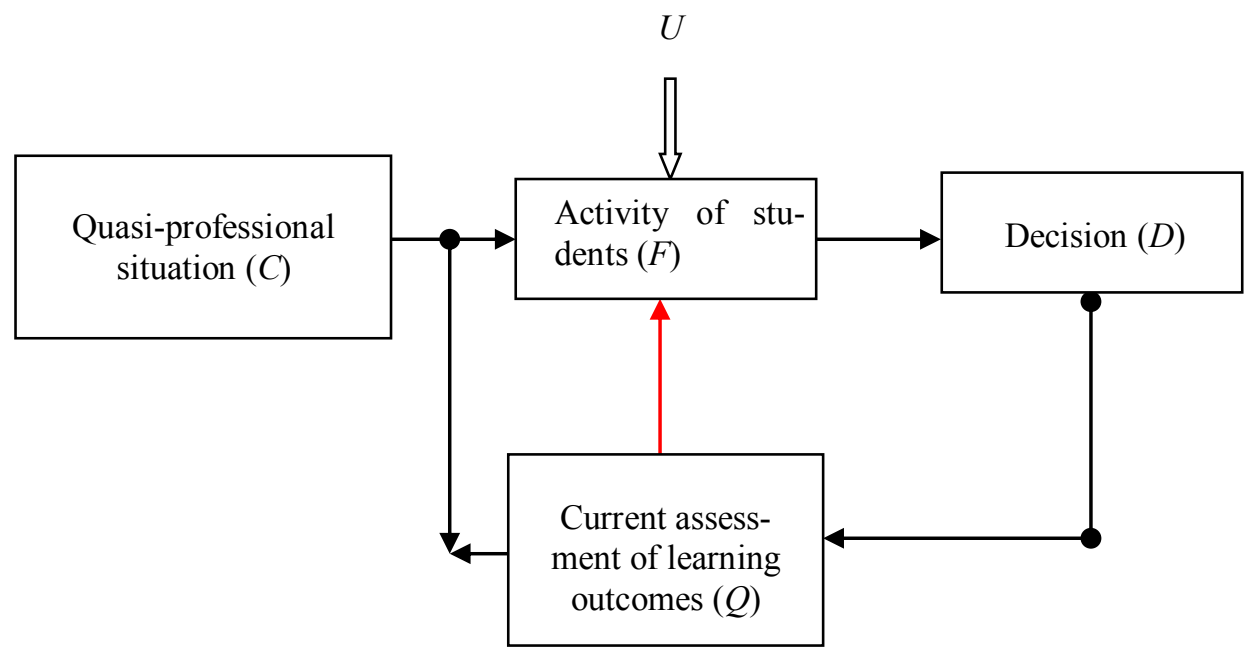

Fig. 1. The activities of students in the framework of competence-oriented tasks.

From the position of a systematic approach [21], the activity of students in solving COT can be represented as a system $\sum$ of with feedback (Fig. 1).

The input of the system $\sum$ receives a quasi-professional situation and task $C$, and at the output many of its decisions D obtained in the process of independent cognitive activity of students F. The qualitative state of this activity is influenced by a finite set of control parameters and actions $\mathrm{U}$, i.e.

$$
\sum=(C, F, U, D)
$$


A quasi-professional situation should motivate and stimulate learners. The task is formulated on the basis of the result of projecting the discipline into selected types of tasks, ways of working with information and key (basic) elements of competencies $e_{i}$ belonging to a finite set of selected competences $K$, which are fully or partially formed within the relevant discipline [20, 22].

To determine the number of technological stages in the formation of competencies in the educational program, a passport and competency cards are created, where they are differentiated into basic elements (levels) $e_{i}$ and determine the planned learning outcomes $P_{i}$. Then they are compared with the substantive part of the discipline. And depending on the degree of compliance, they either exclude or include a discipline where part or all of the competence will be formed $[22,23]$.

From the point of view of the educational and cognitive activity of students, the following COT are distinguished: training, search, and problem, and from the point of view of their content, subject, interdisciplinary, and practical. Depending on the way of working with information, there are nine types of tasks [20]. For practical and laboratory studies recommend the following tasks: comparison; analogy; model; structuring; redundancy; failure and integration [4]. [20]:

The structure and content of the task is determined taking into account the following

- must contain a problem situation;

- must have a gnostic and axiological character;

- may have redundant, incomplete or contradictory information;

- the task must assume the solution invariance and non-determinism of students' actions;

- as a result of the assignment, students must acquire and demonstrate a certain set of knowledge and personal qualities.

The finite set of control parameters and actions $U$ can be represented in the form of three subsystems: teacher styles $T ; R$ resources; $B$ requirements and limitations,

$$
U=(T, R, B)
$$

Before the implementation of COT students, the teacher designs and organizes the learning process: determines the necessary logistical and methodological support and bibliography $(R)$; develops forms for presenting intermediate results, requirements for the report and budget for time for contact and independent work of students $(B)$.

The main task of the teacher is the organization of independent cognitive work, its management and monitoring of students' results. This determines the choice and design of tools, forms of organization, methods and ways of training, focused on the development of certain competencies. All this predetermines the style of the teacher's activities $(T)$, while taking into account the activities of the students, which can be represented in the form of four subsystems,

$$
F=(M, S, I, K S P)
$$

where $M$ - motivation; $S$ - self-organization; $I$ - activity experience and intellectual abilities; $K S P$ - knowledge, skills, practice on discipline.

The teacher monitors the activities of the students $F$ from the moment they receive the task $F\left(t_{0}\right)$ and until its final fulfillment $F\left(t_{n}\right)$.

At the beginning, students evaluate the degree of difficulty of the formulated task. If the quasi-professional situation or the content of the task is difficult to perceive, then, before searching for its solution, the teacher together with the students either complement or simplify the plot of the task. 
In the process of solving COT, based on current assessments of students' actions $F\left(t_{i}\right)$, the teacher adapts his activity: carries out timely consultations, assists in the organization of independent work and makes recommendations on the design and presentation of intermediate results.

Upon completion, it carries out a qualitative assessment of the parameters $F\left(t_{i}\right)$ and the resulting solution to the COT $d_{i}$. Later they are used in assessing current learning outcomes.

The assessment of current learning outcomes can be represented as a direct product of the set of students $J$ and the set of parameters for students' activities $F$, including solutions given by di and marks (points) $O$,

$$
Q=J \times F \times O
$$

It should be noted here that between the competence $k_{i}$ and the learning outcomes $P_{i}$, the following functional relationship is established as [22],

$$
k_{i}=\left(P_{1} \wedge P_{2} \wedge \ldots \wedge P_{n}\right)
$$

where $k_{i}$ - formed competence; $P_{i}$ - learning outcomes in various academic disciplines $(i=$ $1,2, \ldots, n) ; \wedge-$ logical operation (conjunction).

Therefore, $Q \subset P_{i}$ and therefore $Q$ can be taken as the current assessment of the formation of the set of selected competencies $K$.

Based on the above, it follows that the current level of competence formation will depend on the correctness of the comparison of the basic elements (levels) $e_{i}$ of the set $K$ with the content part of the discipline.

Therefore, it can be argued that the main factor in the effectiveness of COT in the educational process is the adequacy of the discipline formed in her competence (s).

Since the differentiation of competence to basic levels and their comparison with the discipline is carried out by the teacher, it can be assumed that the results may vary depending on the level of training of the teaching staff, i.e. the subjective factor will influence the choice of competencies for the discipline.

To test the above assumption, nine working programs on the subject "Metrology, Standardization and Certification" (for undergraduate in the field of "Land Management and Cadastre") were analyzed at eight universities in Russia. The main characteristics of the work programs are presented in Table 1.

Table 1. Main characteristics of the work programs of the discipline "Metrology, standardization and

\begin{tabular}{|c|c|c|c|c|c|c|c|c|c|}
\hline \multirow[t]{2}{*}{ № } & \multirow{2}{*}{$\begin{array}{l}\text { Name of } \\
\text { the } \\
\text { universit } \\
y\end{array}$} & \multirow[t]{2}{*}{ Profile } & \multirow{2}{*}{$\begin{array}{c}\text { Compete } \\
\text { nces* }\end{array}$} & \multirow{2}{*}{$\begin{array}{c}\text { Semes } \\
\text { ter }\end{array}$} & \multicolumn{4}{|c|}{ Training hours } & \multirow{2}{*}{$\begin{array}{c}\text { Number } \\
\text { of labora- } \\
\text { tory works } \\
\text { (practical } \\
\text { tasks) }\end{array}$} \\
\hline & & & & & $\begin{array}{c}\text { Tot } \\
\text { al }\end{array}$ & $\begin{array}{c}\text { Lectur } \\
\text { es }\end{array}$ & $\begin{array}{l}\text { Labor } \\
\text { atory }\end{array}$ & $\begin{array}{l}\text { Prac } \\
\text { tical }\end{array}$ & \\
\hline 1 & $\begin{array}{l}\text { K-na- } \\
\text { ASU }\end{array}$ & $\begin{array}{c}\text { Land } \\
\text { Registry; } \\
\text { City } \\
\text { Cadastre }\end{array}$ & $\begin{array}{c}\text { GCC-4, } \\
\text { PC-5, 8, } \\
10 \text { and } \\
12\end{array}$ & 2 & 108 & 18 & 36 & - & 14 \\
\hline 2 & $\begin{array}{c}\text { RSAU- } \\
\text { MAA } \\
\text { named } \\
\text { after } \\
\text { K.A. } \\
\text { Timirya } \\
\text { zev }\end{array}$ & $\begin{array}{l}\text { Cadastre } \\
\text { of } \\
\text { reclaimed } \\
\text { land }\end{array}$ & $\begin{array}{c}\mathrm{PC}-3,6 \\
\text { and } 12\end{array}$ & 7 & 108 & 17 & - & 34 & 11 \\
\hline 3 & K-na- & Land & GCC-4, & 8 & 108 & 17 & 17 & - & 4 \\
\hline
\end{tabular}
certification". 


\begin{tabular}{|c|c|c|c|c|c|c|c|c|c|}
\hline & ASU & $\begin{array}{l}\text { Registry; } \\
\text { City } \\
\text { Cadastre }\end{array}$ & $\begin{array}{c}\mathrm{PC}-5,8, \\
10 \text { and } \\
12\end{array}$ & & & & & & \\
\hline 4 & KFU & $\begin{array}{c}\text { Land } \\
\text { Managem } \\
\text { ent }\end{array}$ & $\begin{array}{c}\text { GCC-4, } \\
\text { PC-5, } 8, \\
10 \text { and } \\
12\end{array}$ & 8 & 108 & 34 & - & 22 & 10 \\
\hline 5 & SibADI & Geodesy & $\begin{array}{c}\text { GCC-4 } \\
\text { and PC-9 }\end{array}$ & 4 & 108 & 18 & 18 & 18 & 12 \\
\hline 6 & $\begin{array}{c}\text { SSTU } \\
\text { named } \\
\text { after } \\
\text { Gagarin } \\
\text { Yu.A. }\end{array}$ & $\begin{array}{l}\text { City Ca- } \\
\text { dastre }\end{array}$ & $\begin{array}{c}\text { GCC-7, } \\
\text { GPC-3, } \\
\text { PC-5 and } \\
7\end{array}$ & 7 & 72 & 18 & - & 18 & 12 \\
\hline 7 & TPU & $\begin{array}{c}\text { Land } \\
\text { Managem } \\
\text { ent }\end{array}$ & PC-10 & 8 & 108 & 16 & - & 16 & 8 \\
\hline 8 & SSUGT & $\begin{array}{l}\text { Real es- } \\
\text { tate cadas- } \\
\text { tre }\end{array}$ & PC-10 & 1 & 72 & 18 & - & 18 & 7 \\
\hline 9 & IUT & $\begin{array}{c}\text { Real } \\
\text { estate } \\
\text { cadastre; } \\
\text { City } \\
\text { Cadastre }\end{array}$ & PC-1 & 8 & 72 & 11 & - & 22 & 6 \\
\hline
\end{tabular}

Notes:

1) K-na-ASU - Komsomolsk-na-Amure State University;

2) RSAU-MAA named after K.A. Timiryazev - Russian State Agrarian University Moscow Agricultural Academy named after K.A.Timiryazev;

3) KFU - Kazan (Volga region) Federal University;

4) SibADI - The Siberian State Automobile and Highway University;

5) SSTU named after Gagarin Yu.A. - Saratov State Technical University named after Gagarin Yu.A.

6) TPU - Tomsk Polytechnic University;

7) SSUGT - Siberian State University of Geosystems and Technologies;

8) IUT - Industrial University of Tyumen.

* GCC - general cultural competence; GPC - general professional competence; PC professional competence.

It can be seen from table 1 that the discipline is mostly readable in the senior course (fourth) and its volume is 3 credits (108 hours). It has a practice-oriented nature, since the ratio between lectures and laboratory and practical classes is $1 / 2$.

The theoretical part of the discipline includes the basics of metrology, standardization and certification. The main focus is on the first part of the course, which consists of legislative, theoretical and applied sections. Applied metrology is based on the first two sections and is devoted to metrological verification of technical measuring instruments, i.e. the theoretical part of the course in all universities (table 1) corresponds to the training manual, which is recommended for bachelor in the field of land management and cadastre $[1]$.

It highlights the work program of the discipline of Komsomolsk-na-Amure State University: the theoretical and practical parts include the issues of metrological calibration of the main geodetic instruments used in land management and cadastre. In other universities, the section on applied metrology is of a general character. 
The practical part in the work programs of the discipline, mainly, is realized in the form of practical and seminars. And they cover the entire theoretical part of the course (fundamentals of metrology, standardization and certification). The number of practical (laboratory work) is in the range from 4 to 14. On average, 3 hours are allocated for contact work.

With regard to the formed competencies in the discipline, it should be noted that the work programs of the discipline represent a different, different from each other type of composition (general cultural, general professional and professional) and types of competencies (table 1). True, there is a separate case when the competencies coincide, for example, in the universities of TPU and SSUGT. Here the same professional competence is chosen: PC-10. A deeper analysis of the composition of competences in the work programs of the discipline showed that developers, most often, choose GCC-4, PC-5, 10 and 12 [24].

Consequently, it was confirmed that the previously expressed assumption about the possible influence of the subjective factor on the choice of competencies for the discipline. This is also confirmed by the results of the research of the authors [25]: based on the survey, it was revealed that more than $60 \%$ of teachers have difficulty choosing competencies for the discipline.

To solve this problem, the authors [25] developed a program where they implemented the following functions: the choice of training areas; choice of discipline; formation of a competency report for the five areas of undergraduate education (14000, 220700, 240100, 230100 and 241000). Here introduced system characteristics: the integrity of the competence and the degree of importance of the discipline. But, unfortunately, they did not reveal the essence of the algorithm and criteria values.

In this regard, we consider the choice of competencies as the process of projecting a vector on an axis [26].

Imagine a discipline as a set of vectors $V=\left\{v_{1}, v_{2}, \ldots, v_{n}\right\} ; v_{i}=\left\{a_{1}, a_{2}, \ldots, a_{n}\right\}$, where $v_{i}$ are sections or modules of the discipline; $a_{i}$ - questions or items within a section. For axes, we take the basic elements (levels) of competence $e_{1}, e_{2}, e_{3}$ in terms of discipline.

Then the projection of the set of vectors $\mathbf{V}$ to the basic levels of competence we write as

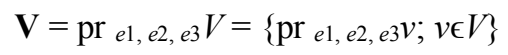

If we project the sets of vectors $\mathbf{V}$ onto the basic elements $e_{i}$ of the set $K$, then we can obtain the following results:

1) if $\forall v_{i} \subseteq V$ does not belong to the set $K$, then there is at least one $a_{1} \in v_{i}$ or several $a_{i}$, that can be represented as a parameter of the function of the basic competence element $\left(e_{j}=\right.$ $\left.f\left(a_{i}\right)\right)$ or $a_{i}=e_{j}$. Then the power of the set of vectors $\mathbf{V}$ will be equal to zero $(\mathbf{m}=0)$ or it will have the minimum value;

2 ) if there are several vectors $v_{i}$ or all that are a subset of the set $K$, with $\forall v_{i} \in V$. Then the power of the set of vectors $\mathbf{V}$ will be equal to the power $V(\mathbf{m}=\mathrm{m})$ or it will have the maximum value.

If $\mathbf{m}=0$, but the competence is selected, then a gross error will be made: the competence cannot be formed in the discipline. As a result, an artificial stage of formation of competence in the educational program is created, and in the work program of the discipline - the levels of knowledge and the planned learning outcomes are incorrectly determined. For example, the choice of competencies should be attributed to this error: GCC-7; GPC-3; PC-3 and PC-9 [24].

The remaining competencies presented in Table 1 have either a direct (GCC-4 and PC5) or indirect (PC-6, 7, 8, 10 and 12) attitude to the discipline. This, in turn, points to another reason, which leads to the erroneous inclusion of competence in the discipline. It consists in the ability to separate the direct and indirect value of the discipline into the formation of competence. 
Obviously, the degree of influence of the discipline on the formation of competence can be determined through the power $\mathrm{m}$ of the set of vectors $\mathbf{V}$. And for this it is proposed to introduce the following criterion values of the degree of influence of the discipline on competence:

1) insignificant - less than or equal to $10 \%$;

2) indirect - more than 10 , but less than or equal to $30 \%$;

3) direct - more than $30 \%$.

Then the choice of competence for the discipline can be carried out according to the formula (7),

$$
k_{i}=\left\{\begin{array}{l}
n o, d m=m \vee d m \geq 0,9 \cdot m ; \\
y e s, d m=0 \vee d m \leq 0,7 \cdot m
\end{array}\right\},
$$

where $d m=m-\mathbf{m} ; m$ and $\mathbf{m}$ are the powers of the set of vectors $V$ and $\mathbf{V}$, respectively.

After applying formulas (6) and (7), they found out that within the discipline "Metrology, Standardization and Certification" (MSC) should be formed, respectively, partially and fully competences: GCC-4 and PC-5 [24], and in the case of implementation of the draft federal standard [27] - GPC-1 and GPC-5.

\section{Experience in the use of competence-oriented tasks in SSUGT}

On the basis of the considered theoretical basis of COT and analysis of the experience of organizing the educational process in universities on the discipline of MSC, the work program included recommended general cultural and professional competences (GCC-4 and PC-5) and selected the following types of tasks:

1) from the perspective of educational and cognitive activity - problematic;

2) from the standpoint of its content - practical.

By the way of working with information, tasks should be complex, consisting of the following types of tasks: comparison; analogy; model; structuring; redundancy and integration.

In determining the content of the actual assignments, we are faced with difficulties, since the discipline of the MSC is taught in the first semester. Students did not study topographic and geodetic works, content of cadastral activities and cadastral registration.

In this regard, it became necessary to develop additional requirements in formulating quasi-professional situations, determining the degree of complexity, scope and content of tasks.

Firstly, all tasks must be in the area of a single quasi-professional situation.

Secondly, the sequence of tasks should be built according to the scheme: from easy to hard.

Thirdly, the knowledge, practical skills and abilities obtained in the process of solving the previous task could be used in the subsequent task.

Fourthly, the time needed for contact and independent work should be necessary and sufficient to form students' readiness and ability to solve professional tasks.

As a result, we developed four integrated COT (table 2) within one quasi-professional situation: to register the right to land and buildings, it is necessary to prepare a boundary and technical plans and draw up a topographic plan for the land use territory. The contractor was given a tape measure of $5 \mathrm{~m}$ long, leveling rail, a digital level and an electronic total station. All devices and equipment have type approval certificates. 
Table 2. Complex competence-oriented tasks

\begin{tabular}{|c|c|c|c|}
\hline № & Theme of the practical task & \multicolumn{2}{|c|}{$\begin{array}{c}\text { The complexity of the training } \\
\text { work, hours }\end{array}$} \\
\cline { 3 - 4 } & & contact & independent \\
\hline 1 & $\begin{array}{c}\text { Metrological calibration of a tape measure 5 m } \\
\text { long }\end{array}$ & 6 & 6 \\
\hline 2 & Metrological calibration of leveling rail & 6 & 6 \\
\hline 3 & Metrological calibration of the digital level & 4 & 6 \\
\hline 4 & Metrological calibration of electronic total station & 4 & 6 \\
\hline \multicolumn{2}{|c|}{ Total } & 18 & 24 \\
\hline
\end{tabular}

The certificate of metrological verification is only on the digital level and electronic total station, which presents the following metrological characteristics: an increase in the telescope, the price of divisions of the installation levels and the standard errors of measurement (elevations, angles and distances).

There is a need to justify the possibility of using the above instruments and equipment in cadastral activities.

After receiving the job, students do the following:- study the normative-technical documents on metrological calibration of the corresponding device or equipment [28 - 33] and the training manual [34];

- make a list of metrological characteristics and forms for registering measurements and presenting the main results of verification;

- carry out an external inspection and approbation of the device (equipment);

- carry out the processing of research results;

- compare the obtained metrological characteristics of the instrument (equipment) with permissible values;

- give a conclusion about the possibility of using the device (equipment).

In the first task, according to the results of research and measurements, the students present the main results of metrological verification in the form of table 3 . Here they get the first practical skills of using calipers and one-meter stroke measures (control line) for determining metrological characteristics.

Table 3. The results of metrological verification.

\begin{tabular}{|c|c|c|}
\hline \multirow{2}{*}{ The name of the characteristics } & \multicolumn{2}{|c|}{ Parameter value } \\
\hline & permissible & actual \\
\hline 1. Testing & & \\
\hline 2. Width, mm & & \\
\hline 3. Thickness, $\mathrm{mm}$ & & \\
\hline $\begin{array}{l}\text { 4. The length of the meter intervals at a temperature of } \\
20^{\circ} \mathrm{C} \text { : }\end{array}$ & & \\
\hline $0-1$ & & \\
\hline $4-5$ & & \\
\hline
\end{tabular}

In the second task, perform three studies, namely:

- determine the random $\Delta_{r}$ and systematic $\Delta_{s y s t}$ of the errors of applying decimeter divisions on the leveling rail (on one side) by formulas (8) and (9)

$$
\Delta_{r}=\Delta o-\Delta_{s y s t}
$$




$$
\Delta_{\text {syst }}=\frac{\sum \Delta o}{N}
$$

where $\Delta o=F_{D}\left(O_{\text {mean }, \mathrm{i}+1}\right)-F_{D}\left(O_{\text {mean }, \mathrm{i}}\right), O_{\text {mean }, i}=\frac{O_{i}^{I}+O_{i}^{I I}}{2} ; O_{i}^{I}$ and $O_{i}^{I I}-$ indication on the control line on the i-th decimeter of the level of the of leveling rail at its first and second position, respectively; $N$ - number of errors $\Delta o ; F_{D}$ - a function that excludes the integer part of the average value $O_{\text {mean, }}$;

- determination of the average meter of the rail (on one side) by the formula,

$$
l_{1 M}=\frac{\sum l_{i}^{\prime}}{n},
$$

where $l_{i}^{\prime}=\frac{l_{i}^{I}+l_{i}^{I I}}{2}+\Delta l_{k, t} ; \Delta l_{k, t}-$ total correction for comparing and control line temperature; $n$-nominal sum of measured lengths in the research process.

Here, as in the first study, the control line is used. Meter intervals are measured twice ( $l_{i}^{I}$ and $\left.l_{i}^{I I}\right)$, but in the forward and reverse directions. If their difference does not exceed $0.10 \mathrm{~mm}$, then proceed to the calculation of the average value. Then measure the next meter interval of the slats. And so, until all three intervals are measured. In the transition from direct to reverse direction, the control line is rotated $180^{\circ}$;

- check the perpendicularity of the heel plane to the rail axis. When checking in the audience install three special crutches. In the future, consistently set on them five points of the heel of the leveling rail, and take readings on the middle thread of the grid of the filaments of the telescope of the digital level. The level is set at a distance of about $15 \mathrm{~m}$ from the crutches. Here students learn for the first time practical skills in taking a reference on the checker rail. In the future, these practical skills students use and develop in the third task.

The third task deals with the determination of the range and the study of the error of the compensator in field conditions. Here, the excess is determined at five positions of a bubble of a circular level.

As a result of such measurements, the random $m_{k}$ and systematic $\sigma_{k}$ errors of the compensator of the level are calculated by the formula (11) and (12),

$$
m_{k}=\sqrt{\frac{\left[d_{i}^{2}\right]}{2 \cdot N}}
$$

where $d_{i}=h_{v i}-h_{o} ; h_{v i}$ and $h_{o}$ - the elevations obtained by tilting and plumbing the axis of rotation of the instrument, respectively; $N$ - number of differences $d_{i}$.

$$
\sigma_{k}=\frac{\sum d_{i}}{S \cdot \tau \cdot N} \rho
$$

where $\tau$-division price of the round level setting level; $\rho$ - one radian in seconds.

In the fourth task, the students, based on the experience of conducting research in the third task, determine the same metrological characteristics as the compensator of the digital level, but for an electronic total station.

In the process of research, the axis of rotation of the electronic total station is tilted 1530 " within the range of operation of the compensator and take readings on a horizontal (vertical) circle. These actions are performed in forward and reverse moves. 
Based on horizontal difference of counts $d_{i}=\beta_{i}^{n}-\beta_{i}^{o}$ for the $\mathrm{i}$-th slope of the axis of rotation of the device, the random error is calculated by the formula (11), and by the formula (13) the systematic error,

$$
\sigma_{k}^{\mp}=\frac{\left\lfloor\Delta_{i}^{\mp}\right\rfloor}{2 \cdot N^{\mp}},
$$

where $\Delta_{i}=\beta_{\text {mean }, i}-\beta_{\text {mean }, o} ; \beta_{\text {mean }, i}=\left(\beta_{i}^{n}+\beta_{i}^{o}\right) / 2 ; \pm$ - denotes negative and positive angles of inclination of the axis of rotation of the device; $\beta_{i}^{n}$ and $\beta_{i}^{o}-$ counting on a horizontal (vertical) circle at the $\mathrm{i}$-th inclination of the axis of rotation of the electronic total station.

After completing the assignment, as part of independent work, each student: answers the control questions in a workbook; writes a conclusion about the possibility of using the device (equipment) and draws up a report.

In the process of completing the assignment and presenting the results of independent work by students, the teacher should evaluate their activity on the basis of the integral point-rating system [35] presented in Table 4.

Table 4. Evaluation of the student's activities in the performance of the task.

\begin{tabular}{|l|l|c|}
\hline \multicolumn{1}{|c|}{ № } & \multicolumn{1}{|c|}{ Parameters of the student's activity } & $\begin{array}{c}\text { Maximum } \\
\text { point }\end{array}$ \\
\hline 1 & Practical activity & 2 \\
\hline 2 & Performs a task as: & 5 \\
\hline 2.1 & performer & 3 \\
\hline 2.2 & assistant & 1 \\
\hline 2.3 & performer and assistant & 5 \\
\hline 3 & The quality of the report on the task & 3 \\
\hline 4 & The quality of design and the correctness of answers to test questions & 5 \\
\hline 5 & $\begin{array}{l}\text { Presentation of the rationale for the use of geodetic instruments and } \\
\text { equipment in cadastral activities }\end{array}$ & 5 \\
\hline \multicolumn{2}{|l|}{ Total } & 20 \\
\hline
\end{tabular}

\section{Discussion}

The experience of using the above comprehensive COT, when conducting practical training on the discipline "MSC" in the fall semester of 2018, showed that they motivate and stimulate students to resolve the quasi-professional situation. As a result, students developed a willingness and ability to determine some metrological characteristics of the main geodetic instruments.

In addition, the effectiveness of the location of complex tasks according to the scheme: from simple to hard. And the inherent ability to use in the current task of practical skills and abilities obtained in the process of solving the previous task, allowed to create a more comfortable learning environment. Students with great interest and more actively embarked on the assignment.

At the same time, some negative aspects were discovered in the organization of practical classes and the level of formation of competencies.

During practical classes, brigades of 4-5 people were formed. This allowed us to implement a group form of organization of the educational process, but not all students could fully engage in the search for a solution to the problem, since the time budget for contact work did not allow it. 
Also, due to the small amount of hours spent on assignments, it was necessary to reduce the amount of research and the number of metrological characteristics. As a result, the students had a low level of competence.

To implement both group and individual forms of organization of the educational process when performing complex competence-oriented tasks (complex tasks) and to increase the level of formation of students' competences, it is necessary:

1) practical exercises should be carried out in the form of laboratory, in which brigades should be formed of no more than two or three people. The total number of hours for contact work should be about 36 hours;

2) increase the volume and composition of research in the tasks;

3) to include in the independent work of students the preparation of essays on standardization and certification, the individual task of processing multiple direct measurements, for example, the determination of measurement errors of the lengths of the sides with a luminometer or electronic total station.

Thus, when organizing the educational process in the discipline "Metrology, Standardization and Certification", for the bachelor degree in "Land Management and Cadastre", the total workload should be three credit units, of which 18 lecture hours and 36 hours of laboratory and practical classes. Two competencies should be formed in this discipline: general cultural (GCC-4) and professional (PC-5).

Laboratory works should consist of four complex competence-oriented tasks, where it is recommended to use the following types of tasks: comparison; analogy; model; structuring; redundancy and integration. All complex tasks can be represented in the form of resolving one quasi-professional situation in the field of cadastral activities.

Independent work of students should include: preparing answers to test questions and a report on the assignment; writing essays and settlement and graphic work.

\section{Conclusion}

Thus, the proposed criterion values in justifying the choice of competence for the discipline and complex tasks will allow to achieve the required level of formation of competencies in the undergraduate degree, i.e. abilities and readiness of students for effective and productive activity in various professional situations.

Further research in this area may be related to the search for the optimal combination of types of tasks in a complex task.

\section{References}

1. D. Gribanov Fundamentals of Metrology, Certification and Standardization (INFRAM, Moscow, 2018)

2. Federal Law № 218-FL "On the State Registration of Real Estate"

3. Yu. Demyanenko, Theoretical and methodological problems of modern education, 101-103 (2013)

4. T. Bezusova, Juvenis scientia 1, 26-29 (2018)

5. D. Shabanova, Current issues of education. Current trends in the quality of continuing education, 55-59 (2016)

6. M. Yanushevskaya, V. Pougat, V. Sinebryukhova, Current issues of education. Current trends in the quality of continuing education, 60-65

7. O. Gritskevich, O. Ushakova, Current issues of education. Current trends in the quality of continuing education, 66-69 (2016) 
8. E. Avrunev, E. Ivantsova, Current issues of education. The role of universities in shaping the information society, 262-265 (2018)

9. L. Trubina, L. Anopchenko, L. Chernovsky, Current issues of education. The role of universities in shaping the information society, 122-127 (2018)

10. N. Silkina, O. Kashnik, Current issues of education. The role of universities in shaping the information society, 220-223 (2018)

11. Yu. Rudenko, Bulletin MUIV, Psychology. Educational resources 1, 4-8 (2012)

12. A. Tsepilova, Young scientist 2(49), 409-411, (2013)

13. M. Lankina, N. Eismont, Bulletin of Omsk University 1, 37-40 (2015)

14. E. Repina, Higher School Pedagogy 2(08), 23-27 (2017)

15. Sh. Bidabadi, Nahid, Journal of advances in medical education \& professionalism 4 , 170-178 (2016)

16. A. Serbati, Tuning Journal for Higher Education 1(3), 19-56 (2015)

17. T. Chacko, Arch Med Health Sci. 2, 247-253 (2014)

18. D. Munoz, D. Araya, Educ. Pesqui, 4(43), 1073-1086 (2017)

19. S. Kunanbayeva, International Journal of Enviromental Scince Education 18(11), 12699-12710 (2016)

20. A. Shekhonina, Competency-oriented tasks in higher education ( $\mathrm{SPb}, \mathrm{NRU}$ ITMO, 2014)

21. F. Peregudov, F. Tarasenko, Introduction to system analysis (Higher school, Moscow, 1989)

22. D. Vasilyeva, M. Katkova, Yu. Kolesnichenko and etc, A system for assessing the level of development of competencies and learning outcomes (Saratov State University, Saratov, 2014)

23. G. Kurbanov, A. Kamalova, Student Science Forum (2014)

24. Order of the Ministry of Education and Science of Russia 1084 (2015)

25. O. Malysheva, R. Gilvanov, Scientific Review. Pedagogical sciences 2, 33-33 (2014)

26. G. Moskinova, Discrete Math. Math for a manager in examples of management (Lotos, Moscow, 2000)

27. Draft Order of the Ministry of Education and Science of the Russian Federation "On Approval of the Federal State Educational Standard of Higher Education in the Field of Preparation 21.03.02 Land Management and Cadastres (Bachelor's Level)" (2017)

28. Instructions for carrying out technological calibration of geodetic instruments. GCINR 17-195-99 (CRIGAPC, Moscow,1999)

29. Instructions for leveling classes I, II, III and IV. GCINR 03-010-02 (CRIGAPC, Moscow, 2003)

30. Russian Federation Standard GOST 7502-98

31. Russian Federation Standard GOST 10528-90

32. Russian Federation Standard GOST R 51774-2001

33. RD 68-8.17-98 Guidance document. Local calibration schemes for topograph measuring instruments - geodetic and cartographic purposes (CRIGAPC, Moscow, 1999)

34. H. Yambaev, N. Golygin, Geodetic Instrumentation. Practical work (UNIX, Moscow, 2005) 
35. V. Kaluzhin, L. Maksimenko, S. Chernonozhkina, Scientific trends: Questions of exact and technical sciences, 25-37 (2018) 